\title{
Adana İli Kiraz Yetiştiriciliği Yapılan Alanlarda Belirlenen Zararlı Böcek Türleri
}

\author{
Burcu Özbek Çatal ${ }^{1 *}$, Zhanerke Amangeldi $^{2}$, Asime Filiz Çalışkan Keçe ${ }^{3}$, Mehmet Rifat Ulusoy ${ }^{4}$ \\ ${ }^{1}$ Çukurova Üniversitesi, Pozantı Meslek Yüksekokulu, Bitkisel ve Hayvansal Üretim Bölümü, Adana, Türkiye (ORCID: 0000-0003-0029-6190) \\ ${ }^{2}$ Cukurova Üniversitesi, Ziraat Fakültesi, Bitki Koruma Bölümü, Adana, Türkiye (ORCID: 0000-0002-9017-8106) \\ ${ }^{3}$ Çukurova Üniversitesi, Ziraat Fakültesi, Bitki Koruma Bölümü, Adana, Türkiye (ORCID: 0000-0002-9330-1958) \\ ${ }^{4}$ Çukurova Üniversitesi, Ziraat Fakültesi, Bitki Koruma Bölümü, Adana, Türkiye (ORCID: 0000-0001-6610-1398)
}

(İlk Geliş Tarihi 16 Ocak 2020 ve Kabul Tarihi 29 Şubat 2020)

(DOI: $10.31590 /$ ejosat.674807)

ATIF/REFERENCE: Özbek Çatal, B. Amangeldi, Z. Çalışkan Keçe, A. F. \& Ulusoy, M. R. (2020). Adana İli Kiraz Yetiştiriciliği Yapılan Alanlarda Belirlenen Zararlı Böcek Türleri. Avrupa Bilim ve Teknoloji Dergisi, (18), 332-337.

$\ddot{\mathbf{O z}}$

Bu çalışma, 2016-2018 yılları arasında Adana ilinde kiraz yetiştiriciliği yapılan 6 ilçede (Pozantı, Karaisalı, Aladağ, Feke, Saimbeyli, Tufanbeyli) yürütülmüştür. Çalışma sonucunda 7 takıma bağlı 17 familyadan 26 zararlı tür saptanmıştır. Bu türlerden bazılarının zaman zaman ekonomik kayıplar oluşturduğu belirlenmiştir.

Tespit edilen zararlı türlerden kirazın ana zararlısı olan Rhagoletis cerasi (L.) başta olmak üzere, Drosophila suzukii (Matsumura), Tropinota (=Epicometis) hirta (Poda), Scolytus rugulosus (Ratzeburg), Myzus cerasi (F.), Archips rosanus (L.) ve Stephanitis pyri (F.)'nin bölgede yaygın olarak bulunduğu ve zarar yaptığı belirlenmiştir.

Anahtar Kelimeler: Kiraz, Drosophila suzukii, Tephritidiae, Drosophilidae, Adana/Türkiye.

\section{Determination of cherry pests in Adana province of Turkey}

\begin{abstract}
This study was carried out the cherry orchards in 6 districts (Pozant1, Karaisalı, Aladağ, Feke, Saimbeyli, Tufanbeyli) of Adana province between 2016-2018. In study were determined 26 pests genus and species belonging to 17 families from 7 order. It has been determined that some of these species cause economic losses from time to time.

Main pest of cherry Rhagoletis cerasi L., Drosophila suzukii (Matsumura), Tropinota (=Epicometis) hirta (Poda), Scolytus rugulosus (Ratzeburg), Myzus cerasi (F.), Archips rosanus (L.) and Stephanitis pyri (F.) were identified as common pests.
\end{abstract}

Keywords: Cherry, Drosophila suzukii, Tephritidiae, Drosophilidae, Adana/Turkey.

\footnotetext{
${ }^{*}$ Sorumlu Yazar: Çukurova Üniversitesi, Pozantı Meslek Yüksekokulu, Bitkisel ve Hayvansal Üretim Bölümü, Adana, Türkiye, ORCID: 0000-00030029-6190, bozbek@cu.edu.tr
} 


\section{Giriş}

Türkiye, yıllık 627.132 tonluk üretimiyle dünya kiraz üretiminin \%25,6'sını karşılayarak birinci sırada yer almaktadır (FAO, 2017). Dünyada kiraz üretiminde ve ihracatında önemli yere sahip olan ülkemizde 2018 yllında 639.564 ton kiraz üretimi gerçekleştirilmiştir (TÜiK, 2018). Ülkemiz, 2018 yılında miktar olarak yaklaşık 70 bin ton, değer olarak ise 162 milyon dolarlık ihracat gerçekleştirmiştir.

Kiraz yetiştiriciliğinde sürdürülebilir bir üretim sağlamak için uygun yetiştirme teknikleri yanında, bitki koruma sorunlarının çözümü de büyük önem taşımaktadır. Özellikle, entomolojik açıdan ürünün verim ve kalitesini önemli oranda etkileyen birçok zararlı böcek bulunmaktadır. Zararlı böcek türleri çiçek ve küçük meyve dökümlerine neden olan faktörler içerisinde önemli yer tutmasının yanı sıra, meyve tutumundan sonra da oluşturduğu zararlar nedeniyle verimi önemli ölçüde düşürmekte, ağacı zayıflatarak bir sonraki yılın ürün miktarını olumsuz yönde etkilemektedirler. Bu zararlılarla mücadelede, kimyasal mücadelenin yoğun bir şekilde kullanımından dolayı da doğal denge bozulmakta ve bu nedenle de zararlıların popülasyon yoğunluğunun yanında buna bağlı olarak da zarar oranları artmaktadır. Modern bir yaklaşımla, zararlı popülasyonlarının ekonomik zarar eşiği altında tutulabilmesi için Entegre Zararlı Yönetimi (iyi tarım uygulamaları-Integrated Pest Management-IPM) hazırlanmaktadır. "Entegre mücadele" programlarının ilk basamağı, var olan mevcut faunanın ortaya çıkarılması ve iyi tarım uygulamalarına esas oluşturacak verilerin elde edilmesi gerekmektedir. Ülkemizde, diğer bölgelerde kirazlarda zararlı ve yararlı türlerin tespiti ile ilgili araştırmalar yapılmıştır (Tezcan, 1995; Özbek ve ark., 1996; Tezcan ve Önder, 1999; Özder,1999; Ulusoy ve ark., 1999; Tezcan ve Pehlivan, 2001; Tezcan ve Önder, 2003; Çınar ve ark., 2004). Adana ili kiraz üretim alanlarında Ulusoy ve ark., (1999)'nın Adana ili Pozantı ve çevresinde kirazlarda zararlı ve yararlı türleri tespit etmek amacıyla yürüttükleri çalışmadan sonra, zararlı türlerin tespiti ile ilgili çalışma yapılmamıştır. Bu bağlamda Karaisalı, Aladağ, Feke, Saimbeyli ve Tufanbeyli ilçelerinde yapılan herhangi bir çalışmaya rastlanmamıştır. $\mathrm{Bu}$ çalışma, kiraz yetiştiriciliğinde mevcut faunanın ortaya çıkarılması ve iyi tarım uygulamaları programı oluşturmada temel veri olarak kullanılması amacıyla da önem taşımaktadır.

\section{Materyal ve Metot}

\subsection{Materyal}

Çalışmanın ana materyalini Adana ili kiraz bahçeleri ile buralardan toplanan böcek türlerin yumurta, larva, pupa ve erginlerine ait örnekler, eşeysel çekici tuzaklar ile çeşitli laboratuvar malzemeleri oluşturmuştur. Kiraz sineği (Rhagoletis cerasi L.) için sarı yapışkan kart şeklinde ve amonyum kapsülü içeren Trece firmasına ait tuzak (Pherocon kit) kullanılmıştır.

\subsection{Metod}

Bu çalışma, 2016-2018 yılları arasında Adana ili Pozantı (Alpu, Ömerli, Fındıklı), Karaisalı, Aladağ, Feke, Saimbeyli ve Tufanbeyli ilçelerinde kiraz bahçelerindeki zararlı böcek türlerini belirlemek amacıyla yürütülmüştür.

\subsubsection{Arazi Çalışmaları}

Arazi çalışmaları, örnekleme amaçlı seçilen kiraz bahçelerinden ilkbahar ve yaz aylarında periyodik olmayan, diğer dönemlerde ise ayda bir kez olmak üzere yapılmış olup, örnekler ağaçların tüm kısımlarından alınmaya çalışılmıştır. Çalışmanın yürütüldüğü alanlar Tablo 1'de verilmiş olup, örneklemeler aşağıdaki yöntemlere göre yapılmıştır.

Tablo 1. Adana ili kiraz bahçelerindeki zararlı türlerin belirlenmesi amacıyla, örnekleme yapılan yerler ve bahçe sayısı

\begin{tabular}{|c|c|c|c|c|c|}
\hline İlçe & Belde/Köy & Bahçe sayısı & İlçe & Belde/Köy & Bahçe sayıs \\
\hline \multirow{4}{*}{ Pozantı } & Alpu & 1 & \multirow{4}{*}{ Saimbeyli } & Gürleşen & 3 \\
\hline & Ömerli & 2 & & Merkez & 1 \\
\hline & Findıklı & 1 & & Obruk & 1 \\
\hline & Hamidiye & 1 & & İslam mah. & 1 \\
\hline \multirow{4}{*}{ Karaisalı } & Hacıkırı & 2 & \multirow{7}{*}{ Aladăg } & Ceritler & 2 \\
\hline & Kızıldağ & 1 & & Meydan & 1 \\
\hline & Fakılar mah. & 3 & & Madenliköy & 2 \\
\hline & Etekli & 1 & & B1 & 1 \\
\hline \multirow{2}{*}{ Tufanbeyli } & Damlalı & 1 & & Değirmencik & 1 \\
\hline & Merkez & 1 & & Yeniköy & 1 \\
\hline Feke & Akkaya & 1 & & Başpınar & 1 \\
\hline TOPLAM & & 15 & TOPLAM & & 15 \\
\hline
\end{tabular}




\section{a) Dal Sayım Metodu}

Bahçeyi temsil edecek şekilde seçilen ağaçlar incelenerek üzerinde zararlıların bulunduğu bitki kısımları (tomurcuk, çiçek, yaprak, meyve) toplanıp önce kese kâğıtları içerisine sonra da polietilen torbalara konularak üzerine etiket bilgileri eklenmiştir.

\section{b) Göz ile inceleme metodu}

Bahçeyi temsil edecek şekilde seçilen ağaçların etrafında dolaşarak bitki organları (fenolojik döneme bağlı olarak, tomurcuk, çiçek, yaprak ve meyve) üzerinde gözle görülen erginler ağız aspiratörü ya da elle toplanıp havalandırma delikleri bulunan kaplar içerisine alınmıştır.

\section{c) Darbe metodu}

Bu yöntem bahçe içerisinde rastgele seçilen ağacın dört yönünden ucuna plastik geçirilmiş sopa ile beşer kez vurularak hareketli olan zararlıların steiner hunisine düşmeleri sağlanmıştır.

\section{d) Tuzak metodu}

Bu çalışmada, Kiraz sineği için sarı yapışkan kart şeklinde ve amonyum kapsülü içeren Trece firmasına ait tuzak (Pherocon kit) kullanılmıştır. Tuzaklar bir hafta aralıklarla kontrol edilip tuzaklar üzerinde yakalanan erginler laboratuvarda değerlendirilmiştir.

\subsubsection{Laboratuvar Çalışmaları}

Bahçelerden alınan böcek örnekleri laboratuvara getirilip önce numaralandırılmıştır. Yaprakbitleri (afit) gibi yumuşak vücutlu olan bireyler \%70'lik alkol içine alınmıştır. Ergin dönemde olmayanlar kültüre alınmış ergin bireyler elde edilmeye çalışılmıştır. Daha sonra böcekler takım, familya ve türlerine göre ayrılıp koleksiyonları yapılmıştır. Bu yöntemlerle elde edilen türlerden genel olarak bilinen ve teşhisli örnekleri koleksiyonumuzda bulunanların tanısı tarafımızdan, tarafımzdan tanısı yapılamayan diğer türler ise konusunda uzman bilim insanları tarafından yapılmıştır.

\section{Araştırma Sonuçları ve Tartışma}

Adana ilinde kiraz yetiştiriciliği yapılan 6 ilçede 2016-2018 yılları arasında yürütülen bu çalışma sonucunda 7 takıma bağlı 17 familyadan 26 zararlı tür saptanmıştır (Tablo 2).

Tablo 2. Adana ili kiraz bahçelerinde 2016-2018 yılları arasında saptanan zararlı türler

\begin{tabular}{|c|c|c|}
\hline TAKIM & FAMILYA & TÜR \\
\hline \multirow[t]{4}{*}{ DIPTERA } & Drosophilidae & Drosophila suzukii (Matsumura) \\
\hline & & Drosophila melanogaster (Meig.) \\
\hline & Tephritidiae & Rhagoletis cerasi (Linnaeus) \\
\hline & & Ceratitis capitata (Wiedemann) \\
\hline THYSANOPTERA & Thripidae & Taeniothrips inconsequens (Uzel) \\
\hline \multirow[t]{2}{*}{ LEPIDOPTERA } & Tortricidae & Archips rosanus (L.) \\
\hline & & Grapholita molesta (Busk.) \\
\hline HYMENOPTERA & Tenthredinidae & Caliroa limacina (Retzius) \\
\hline \multirow[t]{7}{*}{ HEMIPTERA } & Tingidae & Stephanitis pyri (F.) \\
\hline & Aphididae & Myzus cerasi $(\mathrm{F})$. \\
\hline & & Myzus persica (Sulz.) \\
\hline & Pseudococcidae & Phenacoccus aceris (Sig.) \\
\hline & Diaspididae & Melanaspis inopinata (Leonardi) \\
\hline & Pentatomidae & Nezara viridula (L.) \\
\hline & Cicadellidae & Empoasca vitis (Goethe) \\
\hline DERMAPTERA & Forficulidae & Forficula smyrnensis (Serville) \\
\hline
\end{tabular}


Cetonia aurata (L.)

Polyphylla olivieri (Lap.)

Melolontha melolantha (L.)

Anoxia orientalis (Kryn.)

Haplidia transversa (Fabricius)

Scolytidae

Scolytus rugulosus (Ratzeburg)

Curculinoidae

Eusomus ovulum (Germar)

Buprestidae

Capnodis tenebrionis (L.)

Cerambycidae

Cerambyx cerdo (Linnaeus)

Yapılan gözlemler sonucunda, Tablo 2'de verilen türlerden Rhagoletis cerasi (Linnaeus)'nin kirazın ana zararlıs1 olduğu saptanmıştır. Diğer yandan Drosophila suzukii (Matsumura), Tropinota (=Epicometis) hirta (Poda), Scolytus rugulosus (Ratzeburg), Myzus cerasi (F.), Archips rosanus (L.), Stephanitis pyri (F.)'nin en yaygın zararlılar olduğu çalışmalar sırasında gözlemlenmiştir. Ülkemiz kiraz alanlarında yapılan çeşitli çalışmalarda da; Özder (1999), Tekirdağ ili ve çevresindeki kiraz bahçelerinde, Ulusoy ve ark., (1999), Pozantı ve Ulukışla kiraz bahçelerinde, Çınar ve ark., (2004), Elazığ ve Mardin illeri kiraz alanlarında, Ertop ve Özpınar (2011), Çanakkale ili kiraz bahçelerinde, Kaplan (2019), Diyarbakır ili kiraz bahçelerinde benzer zararlıların yaygın olduğunu ve ekonomik düzeyde zarar yaptı̆ı̆ı ıildirilmişlerdir.

Adana ilinde kiraz yetiştirilen alanlarda zarar veren Diptera takımına ait 4 tür bulunmuştur. Bu türlerden $R$. cerasi ve D. suzukii çalışmanın yapıldığı bütün alanlarda yaygın olarak görülmüştür. Kirazın ana zararlısı olan ve kirazda ekonomik ölçüde zarar meydana getiren $R$. cerasi erginleri mayıs ayının sonlarına doğru görülmeye başlayıp meyvelerde kurtlanmaya sebep olmaktadır. Özellikle larva zararı çok önemli olup meyve verim ve kalitesini olumsuz etkilemekte, özellikle de ihracata gidecek ürünlerin pazar değerini düşürmektedir. Çalışmanın yapıldığı bölgedeki üreticilerinin bir kısmının bu zararlı ile herhangi bir mücadele yapmadıkları, mücadele yapan bazı bakımlı bahçelerdeki üreticilerin ise zararlının ergin çıkış zamanlarını dikkate almadan meyvenin ben düşme zamanına göre sadece kimyasal ilaçlama yaparak mücadele ettiği görülmüştür. Feromon tuzak kullanımı ile üreticilerin bu zararlı ile daha etkili mücadele yapmalarının mümkün olduğu bildirilmektedir. (Tezcan ve Gülperçin 2000; Kovancı ve Kovancı 2000; Özbek Çatal ve Ulusoy, 2018).Gerek Avrupa'da ve gerekse Türkiye'de Kiraz sineği ile mücadele edilmediği takdirde ekonomik düzeyde meyve zararına ve verim kaybına neden olacağı, mücadelesinde insektisit uygulamalarına alternatif kültürel metodların meyve zararını önemli derecede azalttığ da yapılan çalışmalarda önemle vurgulanmıştır (Ulusoy ve ark., 1999; Vogt, 2002; Daniel ve Wyss, 2003; Özbek Çatal ve Ulusoy, 2018). Ulusoy et al. (1999) Pozantı yöresinde $R$. cerasi'nin mayıs ayı sonlarında çıkmaya başladığını ve ağustos ayı ortalarına kadar görüldüğünü, Tezcan ve Gülperçin (2000) İzmir ve Manisa illerinde $R$. cerasi' nin ana zararlı olduğunu; nisan ayı sonunda erginlerin ortaya çıktığını ve mayıs ayı sonunda ise ergin çıkışının sona erdiğini tespit etmişlerdir. Diğer taraftan, yaygın ve istilacı bir tür olan D.suzukii'de bölgede kiraz yetiştiriciliği yapılan bütün alanlarda, ağaç üzerinde ve herhangi bir nedenden dolayı yere dökülmüş olan meyvelerde tespit edilmiştir. Zararlı meyvelerde kurtlanmaya sebep olarak ekonomik ölçüde zarar meydana getirmektedir. D. suzukii ülkemizde ilk defa Orhan ve ark., (2016) tarafindan 2014 yllında Erzurum'da tespit edilmiş olup, daha sonra Çanakkale'de Efil (2018) tarafından kayda geçmiştir ve giderek yayılmaya başlamıştır. Bu zararlı Adana kiraz faunası için ilk defa Özbek Çatal ve ark., (2018) tarafından belirlenmiştir. D. suzukii 'nin ABD'de verim kaybının 2008 ve 2009 yıllarında sırasıyla $\% 20$ ve \%80, Avrupa ülkelerinde verim kayıpları Fransa'da \%80, İspanya'da \%100, İtalya'da ise \%30-40 arasında olduğu bildirilmektedir (Bolda ve ark., 2010; Walsh ve ark., 2011; Lee ve ark., 2012). Farklı ülkelerden de birçok araştıııı tarafından zararlıyı tanıma ve çözüm üretebilme amaçlı çalışmalar yürütülmektedir.

Araştırma alanlarında yaygın olarak görülen zararlıların başında $M$. cerasi gelmekte, bu tür rakıma bağlı olarak nisan ayının sonlarından itibaren bahçelerde tespit edilmiştir. Zararlının özellikle yağışlı geçen ilkbahar aylarında koloni oluşturarak sürgün gelişimini bozduğu ve çok fazla miktarlarda fumajine neden olduğu gözlenmiştir. Bu türün diğer illerde de kiraz bahçelerinde yaygın olarak görüldüğ̈̈ ve zarar meydana getirdiği araştırmacılar tarafından da bildirilmiştir (Ulusoy ve ark., 1999; Çınar ve ark., 2004). Elma yaprakbükeni, A. rosanus bölgede yaygın görülen ve zarar yapan bir diğer tür olarak belirlenmiştir. Ancak ekonomik zarar eşiğine ulaşmadığı için üreticiler tarafından bu zararlıya karşı ilaçlı mücadele yapılmamıştır. Zaralının esas zararı larvası tarafından yaprak buketlerinde yaptığı görülmüsstür. Karakteristik olarak yaprakları bükerek birbirine bağlayıp buket haline getirir. Ulu ve Önuçar (1999), kiraz ağaçlarında A. rosanus ile yaptıkları çalışmada zarıının göz, çiçek ve meyvelerde zararın önemli olmadığını esas zararın yaprak buketlerinde olduğunu saptamışlardır. Ertop ve Özpınar (2011), Çanakkale ili kiraz bahçelerinde belirledikleri zararlı türler içerisinde A. rosanus'un önemli zarara neden olduğunu bildirmiştir. Kiraz yazıcıböceği, S. Rugulosus'un kiraz bahçelerinde özellikle bakımsız, zayıf düşmüş ve kurumaya yüz tutmuş ağaçlarda zararlı olduğu tespit edilmiştir. Bu zararlının erginleri, beslenmek için meyve ve sürgün gözlerinin içini oyarak boşaltıp meyve veriminin düşmesine ve ağaçların 2-3 yıl içerisinde ölmesine neden olurlar. Larva döneminde ise dallarda ve gövdede galeriler açarak zararlı olmaktadırlar. S. rugulosus kirazın sekonder bir zararlısı iken, yüksek popülasyon yoğunluklarında pirimer zararlı konumuna geçtiği, sağlıklı fidan ve kiraz ağaçlarına zarar verdiği, zamanında önlem alınmayan ağaçların dal ve gövdelerinde kurumalar görüldüğü bildirilmiştir (Ulusoy ve ark., 1999). Bakla zınnı, $T$. 
hirta erginleri ve zararı ağaçların çiçek açma döneminde yoğun olarak görülmüştür. Zararlı çiçeklerin dişi ve erkek organlarını polen tozlarını, hatta genç yaprak, tomurcuk ve meyveleri yiyerek zararlı olmaktadır. Çiçek döneminde olduğu için arı faaliyetini olumsuz etkilememek için bu zararlıya karşı ilaçlı mücadele önerilmemektedir. Çalışmanın yürütüldüğü bölgede üreticiler, çiçeklenmenin çok yoğun olmadığı bahçelerde ağaçların altına içi su dolu mavi leğenler koyularak popülasyon yoğunluğunu düşürmeye çalışıı̧lardır. Çiçeklenmenin çok yoğun olduğu bahçelerde $T$. hirta popülasyonu yüksek olmasına rağmen üreticilerin birçoğu meyve seyreltmesine neden olduğunu düşünürek önemsememiştir. Kiraz ağaçları yoğun olarak çiçeklendigi için seyreltme meyve kalitesine doğrudan etki etmektedir. Ertop ve Özpınar (2007)'ın Çanakkale ili kiraz bahçelerinde entomolojik sorunları belirlemek amacıyla yapmış olduğu bir anket çalışmasında üreticilerin \%32'si T. hirta, \%19'u S. rugulosus'un zararlı olduğunu bildirmişlerdir. Kaplan (2019), Diyarbakır ili kiraz ağaçlarında, Ertop ve Özpınar (2011) Çanakkale ili kiraz bahçelerinde zararlı türleri belirlemek için yaptıkları çalışmalarında $T$. hirta'nın ekonomik yönden zararlı olduğunu bildirmişlerdir. Tóth et al., (2004) Macaristan'da T. hirta erginlerin yakalanmasında kombineli tuzakların kullanıldığını bildirmiştir. Armut kaplanı, S. pyri, çalışmanın yapıldığı bölgede kiraz dışında başka meyve ağaçlarının da olduğu karışık ve genelde ilaçlanmayan bahçelerde ergin ve nimflerinin yapraklarda yoğun olarak bulunduğu ve ciddi boyutlarda zamanından önce yaprak dökümüne neden olduğu görülmüştür. Bu zararlı, tüm meyve ağaçlarında beslenmekte ve yaprakların alt yüzünde biriken pislikleri ve salgıladıkları tatlımsı maddeler ile solunum yapmasını engellemekte, yaprakların dökülmesine neden olmaktadır. Çam (1993), Tokat ilinin tüm yörelerinde bu zararlı türün yaygın olduğunu, erginlerin ve nimflerin kiraz, vişne ve idris ağaçlarında yaprakların alt yüzeylerini sokup emerek zarar oluşturduğunu belirtmiştir. Çınar ve ark., (2004) $T$. hirta'nın kirazlarda beslendiğini, Ulusoy ve ark., (1999) bu türün kirazlar için ekonomik önem taşıdığını bildirmiştir.

\section{Sonuç}

$\mathrm{Bu}$ çalışma, Adana ili ekonomisi için önem taşıyan kiraz ağaçlarında fitofag türleri belirlemek amacıyla yürütülmüştür. Yürütülen bu çalışma sonucunda kiraz bahçelerinde fitofag türlerden 26 zararlı tür saptanmıştır. Ekonomik öneme sahip olan ve en yaygın görülen türler; Rhagoletis cerasi (Linnaeus), Drosophila suzukii (Matsumura), Tropinota (=Epicometis) hirta (Poda), Scolytus rugulosus (Ratzeburg), Myzus cerasi (F.), Archips rosanus (L.) ve Stephanitis pyri (F.) olarak belirlenmiştir. Bu türlerden, $R$. cerasi (Linnaeus) ve D. suzukii (Matsumura)'nin çalışmanın yürütüldüğü Adana ili kiraz bahçelerinde yaygın olarak bulunduğu ve kirazların ana zararlıları konumunda olduğu tespit edilmiştir. Özellikle, $R$. cerasi ve $D$. suzukii'nin ekonomik anlamda zarar meydana getirmesinde, üreticilerin zararlının ergin çıkış zamanlarını dikkate almadan ilaçlama yapmaları ve hasat zamanını geciktirmelerinin meydana gelen zarar oranı üzerinde büyük önemi olduğu görülmüş̧ür.

Sonuç olarak, kiraz bahçelerindeki zararlı türler, kiraz ağaçlarının; sürgün, yaprak, tomurcuk, çiçek ve meyvelerinde beslenerek verim ve kaliteyi düşürmektedir. Modern bir yaklaşımla, zararlı popülasyonlarını ekonomik zarar eşiğinin altında tutulabilmesi için Entegre Zararlı Yönetimi (iyi tarım uygulamaları-Integrated Pest Management-IPM) hazırlanmaktadır. "Entegre mücadele" programlarının ilk basamağı, var olan mevcut faunanın ortaya çıkarılması ve iyi tarım uygulamalarına esas oluşturacak verilerin elde edilmesidir. Bu amaçla yürüttüğümüz bu çalışma sonucunda, Adana ili kiraz alanlarındaki fitofag türler belirlenmiştir. Ayrıca, iki yıllık sürveyler sonucunda, meyvecilik ile uğraşan üreticilerin, bitki koruma konularının yanı sıra yetiştirme teknikleri açısından da bilgi düzeylerinin yetersiz olduğu görülmüştür. Adana ili kiraz bahçelerinde zararlı mücadelesinde, öncelikle ekonomik öneme sahip türler göz önüne alınmalıdır. Ancak, uygulanacak savaşım yöntemlerinde, diğer zararlı durumundaki türler ve bunları baskı altına alabilecek faydalı türlerin popülasyonları da dikkate alınmalıdır. Bölgedeki kiraz üreticilerinin genel olarak kimyasal savaş yapmamaları doğal dengenin korunması açısından önem arz etmektedir. Bu çalışma sonucunda elde edilen bulgular, hem bilime katkılar sağlamış hem de sonraki çalışmalar için temel veriler elde edilmiştir. Ayrıca, kiraz alanlarında iyi tarım uygulamaları programının oluşturulmasında da yol gösterici olacağı düşünülmektedir.

\section{Teşekkür}

Drosophilidae familyası türlerinin teşhisi için Amir Yassin (CNRS researcher, Institut de Systématique, Evolution, Biodiversité/ France)'e teşekkür ederiz. Bu çalşşma, Çukurova Üniversitesi Bilimsel Araştırma Projeleri Birimi Proje no: FBA-2016-6528 tarafından desteklenmiştir ve Uluslararası Erdemli Sempozyumunda (19-21 Nisan 2018-Mersin) sözlü olarak sunulmuş ve özet olarak yayınlanmıştır.

\section{Kaynakça}

Bolda, M.P., Goodhue, R.E. \& Zalom, F.G., (2010). Spotted Wing Drosophila: Potential Economic İmpact of A Newly Established Pest. Giannini Foundation Agric. Econ, 5-8.

Çam, H., (1993). Tokat ve Çevresinde Kiraz, Vişne ve İdris Ağaçlarında Bulunan Heteroptera Türleri Üzerinde Araştırmalar. Gaziosmanpaşa Üniv. Ziraat Fak. Dergisi, 10: 32-42.

Çatal, B. Ö., \& Ulusoy, M. R., (2018). Investigation İnto Control of Cherry Fruit Fly, Rhagoletis cerasi (L., 1758) (Diptera: Tephritidae), in organic cherry production. Türkiye Entomoloji Dergisi, 42(1), 33-42.

Çatal, B. Ö., ÇALIŞKAN KEÇE, A.F. \& Ulusoy, M. R., (2018). "Adana İli Kiraz Yetiştiriciliği Yapılan Alanlarda Zararlı Böcek Türleri, 109-109”. Uluslararası Erdemli Sempozyumu, 19-21 Nisan 2018.

Çınar, M., Çimen, İ., \& Bolu, H., (2004). Elazığ ve Mardin İlleri Kiraz Ağaçlarında Zararlı Olan Türler, Doğal Düşmanları ve Önemlileri Üzerinde Gözlemler. Türkiye Entomoloji Dergisi, 28 (3): 213-220.

Daniel, C. \& Wyss, E., (2003). "Neue Wege zur Regulierung der Kirschfruchtfliege Rhagoletis cerasi in der biologischen Süsskirschenproduktion. [New approaches to control the cherry fruit fly Rhagoletis cerasi in organic cherry production.], 541- 
542”. Paper at: 7. Wissenschaftstagung zum ökologischen Landbau: Ökologischer Landbau der Zukunft, A-Wien, Institut für ökologischen Landbau (24-26. February 2003, Wien, Universität für Bodenkultur, Wien), 700 pp.

Efil, L., (2018). Çanakkale İli Çilek Alanlarında Yeni Bir Zararlı Drosophila suzukii (Matsumura) (Diptera: Drosophilidae)'nin Yayılış Alanları ve Bulaşıklılığı. Türk Tarım ve Doğa Bilimleri Dergisi, 5 (3), 280-284.

Ertop, S. \& Özpınar, A., (2007). “Çanakkale İli Kiraz Bahçelerindeki Entomolojik Sorunların Belirlenmesi, 116-123”. Lapseki Sempozyumu, 23-24 Haziran 2007.

Ertop, S., \& Özpınar, A., (2011). Çanakkale İli Kiraz Ağaçlarındaki Fitofag ve Yararlı Türler ile Bazı Önemli Zararlıların Popülasyon Değişimi. Türkiye Entomoloji Bülteni, 1 (2): 109-118.

FAO, (2017). Food and Agriculture Organization of the United Nations. http://www.fao.org/home/en/ Erişim tarihi: 07 Ocak 2020.

Kaplan, M., (2019). Diyarbakır İli Kiraz Ağaçlarında Bulunan Zararlı ve Faydalı böcek Türleri ile Bazı Önemli Zararlı Türlerin Doğada Görülme Zamanı. Avrupa Bilim ve Teknoloji Dergisi, (17), 283-289.

Kovanc1, O. B. \& Kovancı, B., (2000). “Bursa ilinde Rhagoletis cerasi L. (Diptera: Tephritidae)'ye karşı savaşım uygulamalarının değerlendirilmesi, 187-195”. Türkiye 4. Entomoloji Kongresi, 12-15 Eylül 2000.

Lee, J.C., Burrack, H.J., Barrantes, L.D., Beers, E.H., Dreves, A.J., Hamby, K.A., Haviland, D.R., Isaacs, R., Richardson, T.A., Shearer, P.W., Stanley, C.A., Walsh, D.B., Walton, V.M., Zalom, F.G. \& Bruck D. J., (2012). Evaluation of Monitoring Traps for Drosophila suzukii (Diptera: Drosophilidae) in North America. Journal of Economic Entomology, 105(4): 1350-1357.

Orhan, A., Aslantaş, R., Önder, B. Ş. \& Tozlu, G., (2016). First Record of the Invasive Vinegar Fly Drosophila suzukii (Matsumura) (Diptera: Drosophilidae) from Eastern Turkey. Turkish Journal of Zoology, 40(2), 290-293.

Özbek, H., Güçlü, Ş., \& Hayat, R., (1996). Kuzeydoğu Tarım Bölgesinde Taş Çekirdekli Meyve Ağaçlarında Bulunan Fitofag ve Predatör Böcek Türleri. Türk Tarım ve Ormancılık Dergisi, 20 (3): 267-282.

Özder, N., (1999). “Tekirdağ İlinde Kiraz Bahçelerinde Bulunan Doğal Düşmanlar ve Bunlardan Yumurta Parazitoiti Trichogramma cacoeciae March. (Hym.: Trichogrammatidae)'nin Yaprak Büken Türlerinde (Lep.: Tortricidae) Doğal Etkinliği Üzerinde Araştırmalar". Türkiye 4. Biyolojik Mücadele Kongresi, 2629 Ocak 1999.

Tezcan, S., (1995). Kemalpaşa (İzmir) Yöresi Kiraz Ağaçlarında Zararlı Buprestidae (Coleoptera) Familyası Türleri Üzerinde Araştırmalar. Türkiye Entomoloji Dergisi, 19 (3): 221-230.

Tezcan, S. \& Önder, F., (1999). Kemalpaşa (İzmir) Yöresi Kiraz Ağaçlarının Heteroptera Faunası Üzerinde Araştırmalar. Ege Üniversitesi, Ziraat Fakültesi Dergisi, 36 (1,2,3):119-124.

Tezcan, S. \& Gülperçin, N., (2000). "İzmir ve Manisa illeri ekolojik kiraz üretim bahçelerinin ana zararlılarından Kiraz sineği Rhagoletis cerasi L (Diptera: Tephritidae) ile savaşta sarı yapışkan tuzaklardan yararlanma olanakları, 167-176”. Türkiye 4. Entomoloji Kongresi, 12-15 Eylül 2000.

Tezcan, S. \& Pehlivan, E., (2001). İzmir ve Manisa İlleri Ekolojik Kiraz Üretim Bahçelerinin Faunası Üzerinde Araştırmalar: Lucanoidea ve Scarabaeoidea (Coleoptera) Türleri Üzerinde Bir Değerlendirme. Ege Üniversitesi, Ziraat Fakültesi Dergisi, 38 (23): 31-37.

Tezcan, S. \& Önder, F., (2003). İzmir ve Manisa İlleri Ekolojik Kiraz Bahçelerinin Faunası Üzerinde Araştırmalar: Heteroptera Takımına Bağlı Türler Üzerinde Bir Değerlendirme. Anadolu Ege Tarımsal Araştırma Enstitüsü Dergisi, 13 (1): $124-131$.

Tóth, M., Schmera, D. \& Imrei, Z. (2004). Optimization of a chemical attractant for Epicometis (Tropinota) hirta Poda 1761. Zeitschrift für Naturforshchung C., 59 (3) : 288-292.

TÜİK, (2018). Türkiye İstatistik Kurumu. Bitkisel Üretim İstatistikleri https://biruni.tuik.gov.tr/medas $/$ kn=92\&locale=tr Erişim tarihi: 07 Ocak 2020.

Ulu, O. \& Önuçar, A., (1999). Investigations on the Economic Threshold of Rose Leafroller, Archips rosanus (L.)(Lepidoptera: Tortricidae). Bitki Koruma Bülteni, 39 (3-4): 103-114.

Ulusoy, M.R., Vatansever, G. \& Uygun, N., (1999). Ulukışla (Niğde) ve Pozantı (Adana) Yöresinde Kirazlarda Zararlı Olan Türler, Doğal Düşmanları ve Önemlileri Üzerindeki Gözlemler. Türkiye Entomoloji Dergisi, 23 (2): 111-120.

Vogt, H., (2002). Expertenkolloquium Kirschfruchtfliege. BBA Dossenheim, 27-28 November 2001. Nachrichtenblatt des Deutschen Pflanzenschutzdienstes, 54: 77-79.

Walsh, D.B., Bolda, M.P., Goodhow, R.E., Dreves, A.J., Lee, J., Bruck, D.V., Walton, M., O’Neal, S.D. \& Zalom, F.G., (2011). Drosophila suzukii (Diptera: Drosophilidae): Invasive Pest of Ripening Soft Fruit Expanding Its Geographic Range and Damage Potential. J Integraten Pest Management, 106: 289-295. 